\title{
Web Searching Factors as Perceived by IT and CS Academics in the Kwazulu-Natal and Eastern Cape provinces of South Africa
}

\author{
PA Tamba-Tamba \\ Department of Information Technology, \\ Walter Sisulu University (WSU) \\ East London, South Africa
}

\author{
SD Eyono-Obono \\ Department of Information Technology \\ Durban University of Technology (DUT) \\ Durban, South Africa
}

\begin{abstract}
Web Searching results from existing web search engines like Google are usually imprecise as they often yield matches to too many irrelevant web pages, making it difficult for some users to find the information they are looking for. But in contrast, many users are still able to effectively use these web search engines in their daily activities. Hence the intend of this paper is therefore to examine factors and their interactive effect influencing the web searching abilities of web engines users specifically for academic staff in the computing disciplines. The study presents the results of a questionnaire based survey of 61 academic staff drawn from Information Technology and Computer Science departments from four Higher Education Institutions in the KwazuluNatal and Eastern Cape provinces of South Africa. The data analysis shows an association between the academic staff members' searching aptitude and their demographic attributes such as academic qualifications, staff positions, and their years of research experience. They also show that there is a correlation between web searching ability and lecturing experience, and between searching ability and English language proficiency. The novel finding of this study compared to existing literature is the impact of lecturing experience on searching ability.
\end{abstract}

\section{Introduction}

The invention in the 1980's of the Personal Computer (PC) added to the invention of the Internet and the World Wide Web (WWW) in the 1990's allowed networks of PCs and users to communicate and share knowledge, data, and information from different parts of the world [3]. At first, there were relatively few documents and web sites, however, as the years goes by, the amount of web page content on the internet has grown phenomenally so that by 2003, there were over one billion static documents on the WWW accessed by over 200 million users worldwide [7]. These web applications and services available on the WWW include emails, web transactions, static pages, social networking and discussion forums, instant messaging, just to name a few. This huge amount of data makes it progressively more difficult for web users from various social demographic backgrounds to find and access information that they required. Search engines are defined by Tümer and colleagues in [18] as programs that return a list of web documents containing users' specified keywords. Due to the rapid growth of the amount of data on the web as well as the increasing number of new end users, huge design challenges arise for achieving effectiveness and efficiency on search engines [13]. Bergman [3] also supports this view by highlighting that one of the challenges of the WWW is that most of the Web's information is buried far down in stacks of dynamically generated sites. Search engines continue to attract a large number of web searchers and are ranked as some of the heavily visited sites worldwide in terms of number of visitors. These visitors are mostly novice internet users who experience even more difficulties to accomplish this search task. Fattahi and colleagues in [6] and Allen in [1] concluded that even experienced users do not always succeed in their web search. Consequently, results generated from search engines are usually imprecise as they often yield matches to thousands of irrelevant web pages, making it hard for some users to find information they are looking for ([8]; [10]). Moreover, end users are also faced with the challenge of first reading the documents retrieved so that they can extract the desired information as the information content is primarily presented in natural languages.

There are two types of internet search techniques: semantic search versus syntactic search. Their difference is based on the fact that semantic search engines are "meaning-based". This meaning-based capability intends to help find dynamically accessible information, and most standard search engines almost never find it in the "deep web" because these search engines create their indices by crawling the web surface, and they only discover static pages linked to other pages [3].

The intend of this study is to analyse the perceived factors that affect the Internet searching ability of academic staff in computing related disciplines taking into account the problems associated with search engine architectures and the gigantic amount of information to search from. The nature of the activities undertaken by academic staffs 
that mostly includes teaching and learning, research, and community engagement requires them to constantly fill in their knowledge and skills by means of internet search. Specifically, academic staffs from the computing field are even a better target for internet search because computing is a continuously changing and innovating discipline

\section{Theoretical Framework}

This study is anchored in the "situated actions, interactive session, and time" theoretical framework (Figure 1) that was developed by Spink from the integration of existing process and users behavioural models in relation to information searching and retrieval [17]. According to this theoretical framework, information searching and information retrieval consist of series of situated actions performed over time by information seekers during interactive web search episodes. Situated actions result from users' decisions on the relevance of their search strategies and of the information collected during their web search sessions. On the other hand, an interactive search session simply refers here to a single web searching experience. Time also called session periods is an essential component of this theoretical model and it is expected to be considered in all stages of the information seeking process. Time is consumed by users either in "thinking processes" such as during the choice of search keywords, or in "mechanical tasks" such as typing or reading. In the current study, the time dimension is mainly represented by research variables measuring information searchers experiences either in the search problem domain (academic activities in this case), in the proficiency of the English language by the web user (language mostly used in web search engines), or in the prior utilization of web search engines. Measuring time using experience is therefore acceptable because experience is usually accumulated over a certain period of time.

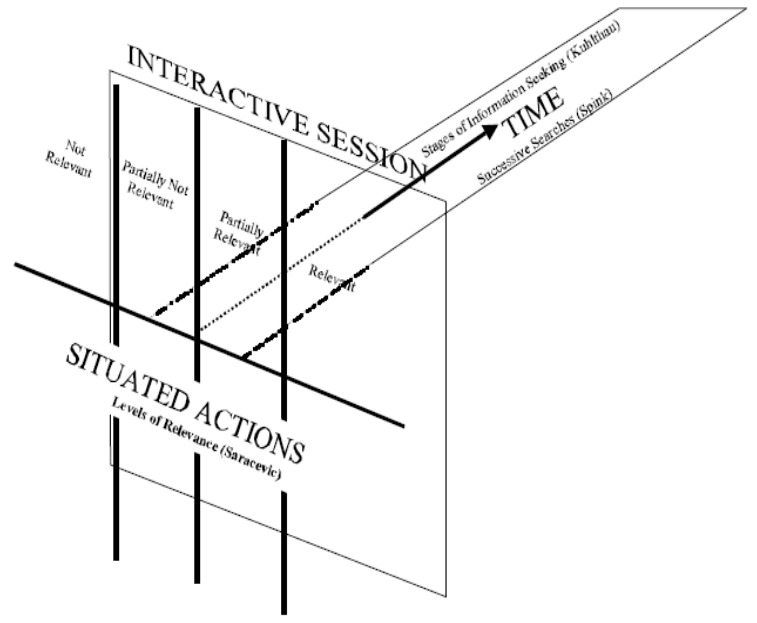

Figure 1. "Situated actions, interactive session, and time" theoretical framework by Spink [17]

\section{Literature Review}

Literature on information retrieval and on the use of search engines focuses different aspects and the following research themes are reviewed for the purpose of this study: online searching success factors, searching strategies and mechanisms, and changes in searching behavioral trends.

\subsection{Online searching success factors}

Jackson and colleagues in [11] measured email applications and web usability against user attitude, motivational, and gender factors by surveying six hundred and thirty (630) Anglo American undergraduate students (403 males and 227 females). The findings reveal among others, that females report more computer anxiety, less computer selfefficacy, and less favourable and less stereotypic computer attitudes than males, and also females use e-mails more than males, but males use the web more than their female's counterparts. Another study by [16] measuring online search success of masters students using experimental search tasks using seven (7) different metrics show that the overall search success in information is low, only $15 \%$ of the students succeed in all three tasks larger percentage of failures was found among students who used search engine. A similar experiment on search success rate based on familiarity (or knowledge) of the domain by twenty-nine (29) students who completed a questionnaire design based on medical and nurse-practitioner theories, concluded that medical students are able to answer more questions correctly than nurse practitioner students before and after searching for information online, and also that medical students are more knowledgeable in medicine than nurses, irrespective of their experience with the use of Internet search.

Theses research findings tell therefore that search session success rate is low among different social and professional internet users and the nature of the search activity varies with demographics like gender.

\subsection{Searching strategies and query reformulation}

Researchers in [15] studied the usability and accessibility of web search engines on a reviewed paper and discovered that most Internet search sessions are spent on the reading of web content by users and their prior knowledge and web experience are key factors for internet. Findings from authors in [2] measuring the behavior of web searchers with regards to their query reformulation shows that on average, about $56 \%$ of search sessions involve some degree of refinement and uptake of feedback increases to $25 \%$. Users also achieve the same level 
of search success regardless of whether feedback is offered or not. Literature also reveals that the proficiency in a specific language influences the search success as the internet content is written in a specific language. Authors in [4] studied the impact of English and other communication skills on search success. In that study, twenty two (22) grade seven learners were asked to search for information using Yahooligans, a search engine for children aged between 7 and 12. The result of the experiment show that at that age group, reading and writing ability of a child influence his or her search success but reading ability alone does not significantly influence his or her searching ability. Other cognitive factor like the level of logical reasoning has been proven to be an influential factor on online searching query formulation. Allen in [1] also found that individuals with high levels of logical reasoning select fewer citations as being potentially useful for internet search.

\subsection{Changes in searching behavioral trends}

Findings from authors in [12] on user searching session pattern on the search engine AltaVista between 1998 and 2002 divulge that there was an increase in the percentage of users viewing more than the first results page, indicating viewing more than the first results page, indicating greater user persistence in locating relevant results. Another research conducted by [5] while analyzing transaction logs on Vivisimo search engine and measuring web session duration exposes that sessions are short and brief in duration, high percentage of search sessions contains one (1) query and lasts for less than one (1) minute in duration.

Researchers in [16] as described earlier also gives evidence that experience affects web information seeking behavior as significant differences exist between expert and novice users in relation to solution time, the number of pages searched and the types of pages accessed. This view is also supported by [19] whose research indicates that learners with web experience are more proficient in locating web sites than are novice web users.

\section{Research Design and Methodology}

This study surveys the factors influencing searching ability of web users. The objectives are to identify, analyze, and mitigate those factors influencing the online search ability of Computer Science (CS) and Information Technology (IT) academics to effectively use online search engines as a teaching and research resource. This research objective is achieved in this study through the analysis of data from a questionnaire based survey of a sample of 61 academic staff from institutions of higher learning. The choice of a survey as a research strategy for this research is mainly justified by the fact that surveys are usually considered as a simple and cost effective research strategy whereby a large amount of data can be collected within a reasonable time frame [9], and secondly because surveys are suitable for perceptions analysis studies as it is the case for this research. This sample was drawn from IT and CS departments in four universities located in the KwaZulu-Natal (KZN) and Eastern Cape (EC) provinces of South Africa. The KZN province has four universities and three of them were selected in this study. The fourth university was not included in the research because their IT department does not offer any postgraduate program. The EC Province also has four universities and only one of them was selected in the study due to geographical distance constraints between these universities.

\subsection{Sampling}

The target population of the study consists of academic staff in the field of Information Technology (IT) and Computer Science (CS), two of the five main classifications of computing disciplines. For convenience, this academic staffs were selected from four universities around the area where the research took place. In this study, research participants were to be selected from the chosen institutions using a non-probabilistic sampling method. It was not possible to choose a probabilistic sampling method because the researcher did not have beforehand a complete list of potential research respondents from which it would have been possible to operate a random selection. Thus the sampling method of this research was a mixture of convenient sampling and self-selection sampling: In some cases, the research participants were approached at the end of departmental meetings, and in some other instances, the researchers met individual respondents in their offices.

\subsection{Research Variables}

The questionnaire consisted of six sections: all other five sections (except from the first section) represented factors that were assumed from the reviewed literature, to have a possible impact on the online searching abilities of an academic staff. It is constituted of rated questions or statements.

The following research variables were measured by relevant sections of the questionnaire: Demographics, Lecturing Experience, Research Experience, English Language Ability, Prior Research Experience, and Web Searching Ability. Each research variable had 10 questionnaire items representing statements intended to measure how an academic staff assesses his or her level of capacity for that variable. For example, the English language ability items measured academic staff aptitude with 
regards to their writing, speaking, and reading proficiency, how easily the respondent staff could spot mistakes while reading, the extent to which the staff used the language out of his or her work environment, et cetera. For each statement, each respondent staff was requested to auto-assess his or her aptitude using a 5-point Likert rating scale ranging from 'Strongly Agree' (5) to 'Strongly Disagree' (1).

\subsection{Data Analysis}

The completion of the questionnaire by the respondents yielded research data that was analyzed with the help of the PASW STATISTICS 18.0 (SPSS) statistics software package. The first phase of the data analysis consisted in the testing of the reliability and validity of the collected data. Then, a number of statistical tests, specifically descriptive and inferential, were executed on the data. Descriptive statistics such as proportions, means and frequencies were computed for only variables that has passed the reliability and validity tests. Furthermore, correlations between Likert-scale based research variables were tested using the Pearson's correlation tests and linear regression methods. One way ANOVA tests were also used to test the association between each of the demographic profile items (factors) and the web search ability (dependent variable). Research variables found to be significant for the Pearson's correlation were combined with those having passed the one way ANOVA test for a further ANCOVA test for analyzing their interactive effect on the dependent variable. All these tests were done with a confidence level of $95 \%$ unless otherwise specified significant $p$-value for any given test should be in the range value between 0.00 and 0.05 .

\section{Result}

\subsection{Reliability and Validity}

Reliability is defined as the consistency of a variable's measurement, or the degree to which an instrument measures the same way each time it is used under the same condition with the same subjects. On the other hand, validity refers to whether the questionnaire or survey measures what it intends to measure [14]. Both reliability and validity test are important and the validity of a questionnaire relies first and foremost on its reliability. The reliability test of the questionnaire data was done by calculating the Cronbach's coefficient alpha $(\alpha)$ for each Likert scale based section of the questionnaire. Data extracted from each research questionnaire section was deemed to be reliable only when its alpha $(\alpha)$ coefficient was greater than 0.700 . Data from each of the questionnaire section was deemed valid when the following three conditions were met: Determinant D greater than $10^{-5}$; the Kaiser Meyer Olkin (KMO) measure of sampling adequacy is greater than 0.500; and only one (1) component extracted by the section's items after factor analysis [14]. Table 1 summarizes the questionnaire items for all the valid and reliable research variables. Additionally to the validity of each variable, the testing of the overall validity of the questionnaire data was conclusive using the factor analysis of all the reliable and valid items from the Likert scale based independent variables.

Table 1. Reliability and Validity tests results

\begin{tabular}{|c|c|c|c|c|}
\hline $\begin{array}{c}\text { Variables } \\
\text { (Abbreviation) }\end{array}$ & Items & $\boldsymbol{\alpha}$ & KMO & $\begin{array}{c}\text { Determinant } \\
\text { (D) }\end{array}$ \\
\hline $\begin{array}{c}\text { Lecturing } \\
\text { Experience } \\
\text { (LE) }\end{array}$ & $\begin{array}{c}12,14, \\
15\end{array}$ & 0.757 & 0.651 & 0.449 \\
\hline Research & 23,24, & 0.925 & 0.833 & 0.006 \\
Experience & 25,26, & & & \\
(RE) & 27,28 & & & \\
\hline English & 31,32, & 0.783 & 0.805 & 0.085 \\
Language & 33,34, & & & \\
Ability (ELA) & 36 & & & 0.27 \\
\hline Prior search & 42,43, & 0.806 & 0.767 & \\
Experience & 44,45 & & & \\
(PSE) & & & & \\
\hline Web Searching & 51,53, & 0.862 & 0.822 & 0.069 \\
Ability (WSA) & 54,57, & & & \\
& 58,59 & & & \\
\hline
\end{tabular}

\subsection{Descriptive statistics}

Descriptive statistics gathered during data analysis revealed that: almost a 4 to 6 ratio between female and male, a majority of staff in the research sample were from Information Technology (77\%) as compared to Computer Science (23\%); half of the total number of respondent $(52 \%)$ held the position of Lecturer and only six of the $61(9.8 \%)$ were Doctorate $(\mathrm{PhD})$ holders; a majority of staff were under qualified (below Masters degree) middle age male staff in junior positions with considerable years of lecturing experience but with little research experience.

A mean analysis of each of the likert scale research variable was performed and table 2 presents the results of those descriptive statistics. Table 2 reveals that the research participants perceive their lecturing experience (mean of 11.7 out of 15), their English language proficiency (mean of 21.6 out of 25 ), and their searching abilities (mean of 23.3 out of 30 ) as high (more than $75 \%$ ), but their research (mean of 12.2 out of 30) and prior searching experiences (mean of 11.0 out of 20) are perceived as moderate. Table 2 also presents other descriptive tests results like the variance or standard deviation that shows how much the choice of perceptions varied among the research respondents. 
Table 2. Likert scale-based research variables descriptive statistics

\begin{tabular}{|c|c|c|c|c|c|}
\hline & $L E$ & $R E$ & $E L A$ & $P S E$ & WSA \\
\hline Mean & $\mathbf{1 1 . 7}$ & $\mathbf{1 2 . 2}$ & $\mathbf{2 1 . 6}$ & $\mathbf{1 1 . 0}$ & $\mathbf{2 3 . 3}$ \\
\hline Variance & 7.5 & 41.7 & 8.3 & 13.9 & 17.6 \\
\hline Minimum & 3 & 6 & 12 & 4 & 14 \\
\hline Maximum & $\mathbf{1 5}$ & $\mathbf{3 0}$ & $\mathbf{2 5}$ & $\mathbf{2 0}$ & $\mathbf{3 0}$ \\
\hline
\end{tabular}

\subsection{Inferential Statistics}

The results of the inferential statistical tests performed in this study include the Pearson's correlation test, the multiple regression analysis tests, one way ANOVA tests, and the ANCOVA tests as discussed below.

5.3.1. Pearson's Correlation Test. A two-tailed Pearson's correlation test was performed in order to evaluate relationships between the Likert scale based research variables. Table 3 presents the results of these tests and uses shaded cells to show variables with a significant correlation with the dependent variable. Due to the length of the variable's names being long to fit on the table, columns' and rows' headings are made of their abbreviations: for example Lecturing Experience is abbreviated as LE.

Table 3 shows that the correlation between English Language Ability and Web Searching Ability is significant at $99 \%(\mathrm{p}=0.003)$ because its Pearson's coefficient has a double star superscript $(* *)$, and staffs' Lecturing Experience ( $p=0.019)$ also presents a significant correlation $\mathrm{p}$-value with Web Searching Ability. Thus each of these two variables has a linear correlation against the dependent variable Web Searching Ability. On the other hand, the following variables do not show a linear correlation with the Web Searching Ability variable because their p-value is not significant: Research Experience $(p=0.489)$, and Prior Searching Experience ( $p=0.298)$.

It is also important to note that, in the current study, correlations involving the independent variables by themselves were not analyzed further as these tests fall out of the defined objectives: for example, on table 3, Lecturing Experience does correlates to English language Ability although their p-value equals to $0.024<0.05$ is significant (see underlined values).

The Pearson's Correlations test only presents a relationship between two variables but does not clearly states if one variable actually predicts the change on the another one including the dependent variable. Thus other inferential statistical tests are performed as described below in order to be able to identify those predicting factors or variables whose variance can change the behavior on the dependent variable.
Table 3. Pearson's correlation test results between research variables

\begin{tabular}{|c|c|c|c|c|c|c|}
\hline \multicolumn{2}{|c|}{$\begin{array}{c}\text { Research } \\
\text { Variables } \\
\text { Abbreviati } \\
\text { ons }\end{array}$} & $L E$ & $R E$ & $E L A$ & $P S E$ & $\begin{array}{c}W S \\
A\end{array}$ \\
\hline \multirow[t]{3}{*}{$L E$} & $\mathrm{PC}$ & 1 & & & & \\
\hline & Sig. & & & & & \\
\hline & $\mathrm{N}$ & 61 & & & & \\
\hline \multirow[t]{3}{*}{$R E$} & $\mathrm{PC}$ & .240 & 1 & & & \\
\hline & Sig. & .062 & & & & \\
\hline & $\mathrm{N}$ & 61 & 61 & & & \\
\hline \multirow{3}{*}{$\begin{array}{c}E L \\
A\end{array}$} & $\mathrm{PC}$ & $.288^{*}$ & .071 & 1 & & \\
\hline & Sig. & .024 & .584 & & & \\
\hline & $\mathrm{N}$ & 61 & 61 & 61 & & \\
\hline \multirow[t]{3}{*}{$P S E$} & $\mathrm{PC}$ & -.106 & $-.277^{*}$ & $-.301^{*}$ & 1 & \\
\hline & Sig. & .416 & .031 & $\begin{array}{l}.019 \\
\end{array}$ & & \\
\hline & $\mathrm{N}$ & 61 & $\overline{\underline{61}}$ & $\underline{\underline{61}}$ & 61 & \\
\hline \multirow[t]{3}{*}{ WSA } & $\mathrm{PC}$ & $.299^{*}$ & .090 & $.376^{* *}$ & -.135 & 1 \\
\hline & Sig. & .019 & .489 & .003 & .298 & \\
\hline & $\mathrm{N}$ & 61 & 61 & 61 & 61 & $\begin{array}{l}6 \\
1\end{array}$ \\
\hline \multicolumn{7}{|c|}{ *. Correlation is significant at the 0.05 level (2-tailed) } \\
\hline
\end{tabular}

5.3.2. Regression Analysis. This test was performed in order to determine the regression correlation equation of the type $Y=B X+$ Constant which defines the linear equation between the dependent variable $(\mathrm{Y})$ and each of its independent variable (X). In the regression coefficient table shown by table 4 , the model reveals that only the English Language Ability is a predictor directly influencing the Web Searching Ability of staff members as its p-value is $0.022(p<0.050)$. This table also reveals that the linear regression equation is positive because the slope (B coefficient) is +0.452 and the Constant is 9.967. Therefore the regression equation between these two variables is given by the equation 1 below:

$$
W S A=0.452 * E L A+9.967 \text { (equation } 1)
$$

Table 4. Regression's Coefficient table

\begin{tabular}{|l|c|c|c|c|c|}
\hline \multirow{2}{*}{ Model } & \multicolumn{2}{|c|}{$\begin{array}{c}\text { Unstandardized } \\
\text { Coefficients }\end{array}$} & $\begin{array}{c}\text { Standardized } \\
\text { Coefficients }\end{array}$ & \multirow{2}{*}{ Sig. (p) } \\
\cline { 2 - 4 } & $\mathrm{B}$ & Std. Error & Beta & $\mathrm{t}$ & Sig \\
\hline 1 (Constant) & 9.967 & 5.019 & & 1.986 & .052 \\
LE & .313 & .199 & .204 & 1.574 & .121 \\
RE & .009 & .084 & .014 & .112 & .911 \\
ELA & .452 & .192 & .311 & 2.359 & .022 \\
PRE & -.018 & .148 & -.016 & -.123 & .903 \\
\hline
\end{tabular}

a. Dependent Variable: WSA

5.3.3. The 1-way Analysis Of Variance (ANOVA). Recalling that the first section of the questionnaire captured demographic background data of the research respondent, those items of the questionnaire were analyzed so as to measure their effect as factor to predict the change on their web searching ability. 
An ANOVA analysis was therefore performed all 10 items.

Table 5. Levene's Test of Equality

\begin{tabular}{|l|l|l|l|}
\hline$F$ & df1 & df2 & Sig. \\
\hline 3.406 & 4 & 56 & .015 \\
\hline
\end{tabular}

The ANOVA analysis produces a number of tables and graphs but the relevant figures for this study are presented as the results of the Levene's tests for equality of variance and of the tests between subjects' effect on tables 5 and 6 respectively. Table 5 represents the Levene's Test of Equality of Error Variances which allows the data to be redeemed valid for the ANOVA test based on the value from the Mean test, the differential-test, or the Sig. test.

Table 6. ANOVA test of between subject

\begin{tabular}{|c|c|c|c|c|}
\hline Source & $\begin{array}{l}\text { Type } \\
\text { III } \\
\end{array}$ & $\mathrm{df}$ & $\begin{array}{l}\text { Mean } \\
\text { Square }\end{array}$ & Sig. \\
\hline Corrected Model & 789.86 & 33 & 23.93 & .010 \\
\hline Intercept & 727.6 & 1 & 727.64 & .000 \\
\hline $\begin{array}{l}\text { Academic } \\
\text { Department }\end{array}$ & 13.174 & 1 & 13.174 & .258 \\
\hline Gender & 5.680 & 1 & 5.680 & .455 \\
\hline Age Group & 26.49 & 4 & 6.600 & .620 \\
\hline Position & 259.54 & 6 & 43.257 & .003 \\
\hline $\begin{array}{l}\text { University } \\
\text { Affiliation } \\
\end{array}$ & 71.366 & 3 & 23.789 & .089 \\
\hline $\begin{array}{c}\text { Years Of } \\
\text { Experience in } \\
\text { Lecturing }\end{array}$ & 43.56 & 4 & 10.889 & .376 \\
\hline $\begin{array}{c}\text { Years Of } \\
\text { Experience in } \\
\text { Research }\end{array}$ & 189.54 & 4 & 47.386 & .005 \\
\hline $\begin{array}{c}\text { Highest } \\
\text { Qualification } \\
\end{array}$ & 156.28 & 5 & 31.257 & .022 \\
\hline $\begin{array}{c}\text { Primary Second } \\
\text { Language }\end{array}$ & 201.58 & 3 & 67.196 & .001 \\
\hline Tertiary Language & 101.3 & 2 & 50.648 & .013 \\
\hline Error & 266.83 & 27 & 9.882 & \\
\hline Total & $\begin{array}{c}34159 . \\
0 \\
\end{array}$ & 61 & & \\
\hline Corrected Total & 1056.7 & 60 & & \\
\hline
\end{tabular}

Table 5 therefore reveals that the ANOVA test performed is significant because its overall significant value is 0.015 (Sig. $=0.015<0.05)$. This substantiates that the data used on this study is deemed valid for ANOVA analysis test.

As already mentioned, in addition to the Levene's Test of Equality of Error Variances table, the ANOVA test also generates the table of between subject effects that shows how individual factor grouping predict the dependent variable.

Table 6 represents the result of the test of between subject and shows that out of the ten (10) biographical profile items, only the following five (5) items are predicting factors of web searching ability because they have a p-value less than 0.05 : position (Sig. $=0.003)$, years of research experience (Sig. =0.005), highest qualification (Sig. =0.022), primary and second language (Sig. $=0.001$ ), and tertiary language $($ Sig. $=0.013)$.

5.3.4. The Analysis of Co-variance (ANCOVA). Let's recall from the previous findings that the Pearson's correlation analysis test above revealed a correlation between the Lecturing Experience variable and the dependent variable Web Searching Ability, and in addition to a correlation between the English Language Ability and Web Searching Ability of the academic staff. The multiple regression tests also confirmed that once again, the English Language Ability variable is a predictor of staff Web Searching Ability; therefore there was a need to further analyze differences in Web Searching Ability, Lecturing Experience, and English Language Ability as covariant and also look at their interactive effect within and between the different groups for each of the observed five (5) fixed factors validated by the ANOVA test. An ANCOVA test was therefore performed. Due to the interactive effect of the fixed factors, the tables produce for the ANCOVA analysis was too long as to fit on less than two (2) pages on this document, the researchers narrate the findings.

Firstly, Levene's Test of Equality of Error Variances table shows all tests (Mean test, differential-test, or the Sig) indicator valid. As reported in the previous statistical tests, the significant value (Sig.) test on its own is enough. Levene's Test shows a corrected model of the data with a Significant value of 0.022 (Sig. $=0.022<0.05$ ) confirming that the test was deemed valid for ANCOVA analysis.

Secondly, the result of the ANCOVA test of between subject reveals that taking into account the combined effect of demographic factors and of the Likert-scale based research co-variables (English Language Ability and Lecturing Experience), the Web Searching Ability of academic staff can be predicted by their position (Sig. $=0.007)$, the language of their tertiary education (Sig. = 0.013), and by their English Language Ability (Sig. $=0.045)$. 


\section{Discussion}

The different statistical tests were performed on data items of the questionnaire that were deemed to be reliable and valid. This validity and reliability test extracted only one component for factor analysis. Most of the research findings (be descriptive or inferential tests) emanated from the study are supported by existing literature except for the one on searching success rates and the one on the effect of gender and age on online searching capability of the user. As recorded in literature [16], the overall search success of online information is low and is only in the range of $15 \%$ for students while the academic in this research web search capability is high as shown in table 2. These difference findings could be attributed and explained to and by the use of different methodologies in the two studies.

The study also reveals a novel finding on the effect of Lecturing Experience on Web Searching Ability as shown by the Pearson's correlation analysis test. This finding reveals that the nature of the type of teaching and learning enablers (like e-learning tool, Problem based Learning, Recognition of Prior Learning, etc) that is used might have been the originator to this particular result as these enablers have a kind of incorporated online searching process.

Ideas for future research and recommendations on how to improve web searching performance include mentoring programs of junior academic staff by more experienced staff, training of novice web searchers, designing and using semantic search systems both in English and in local African languages, publishing more web content in local African languages, and triangulating various research strategies for the analysis of the usability of web search engines.

\section{Conclusion}

This study adds evidence to the existing body of knowledge in support of the claim that web searching ability is affected by some demographic factors like the position the person hold in the institution of higher learning, language factors, and by cognitive factors linked to users' expertise and experience in the domain being searched. In the computing related disciplines, as a case study from four Universities in the Kwazulu-Natal and Eastern Cape provinces of South Africa, finding reveals that staff's position, the language proficiency at their tertiary education, and their English Language Ability are predictors of his or her online search aptitude. The limitations of this study are mainly related to the fact that its results are based on the analysis of perceptions and not on experimental data. However, most of its research findings are supported by existing literature, and plausible explanations can be made where they are not. The novelty of this study resides in the choice of its research population (IT and CS academic staff) and on the identification of new work related factors predicting web searching ability and probably originated from the teaching and learning enablers.

\section{Reference}

[1] B. Allen, "Cognitive differences in End User Searching of a CD-ROM Index," 15th Ann. Int'1 Special Interest Group in Information Retrieval (SIGIR), 1992/Denmark6/92.

[2] P. Anick, "Using Terminological Feedback for Web Search Refinement - A Log-based Study", ACM Special Interest Group in Information Retrieval (SIGIR) 2003, July 28-August 1, Toronto, Canada.

[3] M. K. Bergman, "The Deep Web: Surfacing Hidden Value". White paper available online at http://beta.brightplanet.com/deepcontent/tutorials/DeepWe b/index.asp (31 December 2010)

[4] D. Bilal, "Children's Use of the Yahooligans! Web Search Engine: Cognitive, Physical, and Affective Behaviors on Fact-Based Search Tasks," Journal of The American Society For Information Science. Vol. 51, Issue 7, 2000, pp.646-665.

[5] W. Cohen, A. McCallumx, and D. Quass, "Learning to Understand the Web," Bulletin of the IEEE Computer Society Technical Committee on Data Engineering, Vol. 23, No. 3, 2000, pp. 17-24.

[6] R. Fattahi, C. S. Wilson, and F. Cole, “An alternative approach to natural language query expansion in search engines: Text analysis of non-topical terms in Web documents," Information Processing and Management Vol. 44, 2008, pp. 1503-1516.

[7] D. Fensel, J. Hendler, H. Lieberman, and W. Wahlster (2002). "Creating of Semantic Web,", available on line http://www.cs.vu.nl/ dieter/ftp/paper/mit.introduction.pdf (July 9, 2009).

[8] L. Gugerty, C. Treadaway, and J. S. Rubinstein, "Individual Differences in Internet Search Outcomes and Processes". CHI 2006, April 22-27, 2006, Montréal, Québec, Canada. ACM 1-59593-298-4/06/0004.

[9] P.Van Schaik and J. Ling "Design Parameters of Rating Scales for Web Sites", ACMTransactions on Computer-Human Interaction, Vol. 14, Issue 1, Article 4, 2007.

[10] G. J. Hwang, P. S. Tsai, C.C. Tsai, and J.C.R. Tseng, "A novel approach for assisting teachers in analyzing student web searching behaviors". Journal of Computers \& Education. Vol. 51, 2008, pp. 926-938.

[11] L.A. Jackson, K. S. Ervin, P. D. Gardner, and N. Schmitt, "Gender and the Internet: Women communicating and men searching," Sex Roles, Vol. 44, No 5/6, 2001, Academic Research Library. Michigan University, USA 
[12] B.J. Jansen, A. Spink, and J. Pedersen, “A Temporal Comparison of AltaVista Web Searching," Journal Of The American Society For Information Science And Technology. Vol. 56, No. 6, 2005, pp. 559-570.

[13] B. Kules, and B. Shneiderman, "Users can change their web search tactics: Design guidelines for categorized overviews," Journal of Information Processing and Management, Vol. 44, 2008, pp. 463-484.

[14] A. Large, J. Beheshti, and T. Rahman, "Gender differences in collaboration Web searching behavior: An elementary school study," Journal of Information Processing and Management, Vol. 38, (2002), pp. 427443.

[15] A. T. Lee, "Web Usability A Review of the Research," SIGCHI Bulletin, Vol. 31, No. 1, 1999, pp. 3840.

[16] R. Nachmias, and A. Gilad, "Needle in a Hyperstack: Searching Information on the World Wide Web," Journal of Research on Computing in Education, 2001.

[17] A. Spink, "Web Search: Emerging Patterns," IEEE Library Trends, Vol.52, No. 2, 2003, pp. 299-306.

[18] D. Tümer, M. A. Shah, and Y. Bitirim, "An Empirical Evaluation on Semantic Search Performance of KeywordBased and Semantic Search Engines: Google, Yahoo, Msn and Hakia," IEEE computer Society Fourth International Conference on Internet Monitoring and Protection, 2007, pp. 51-55.

[19] W. Lazonder, J.A. Biemans Harm, and I.G.J.H Wopereis. 'Differences between Novice and Experienced Users in Searching Information on the World Wide Web'. Journal of the American society for Information Science. Vol. 51, No. 6, 2000, pp. 576-581. 